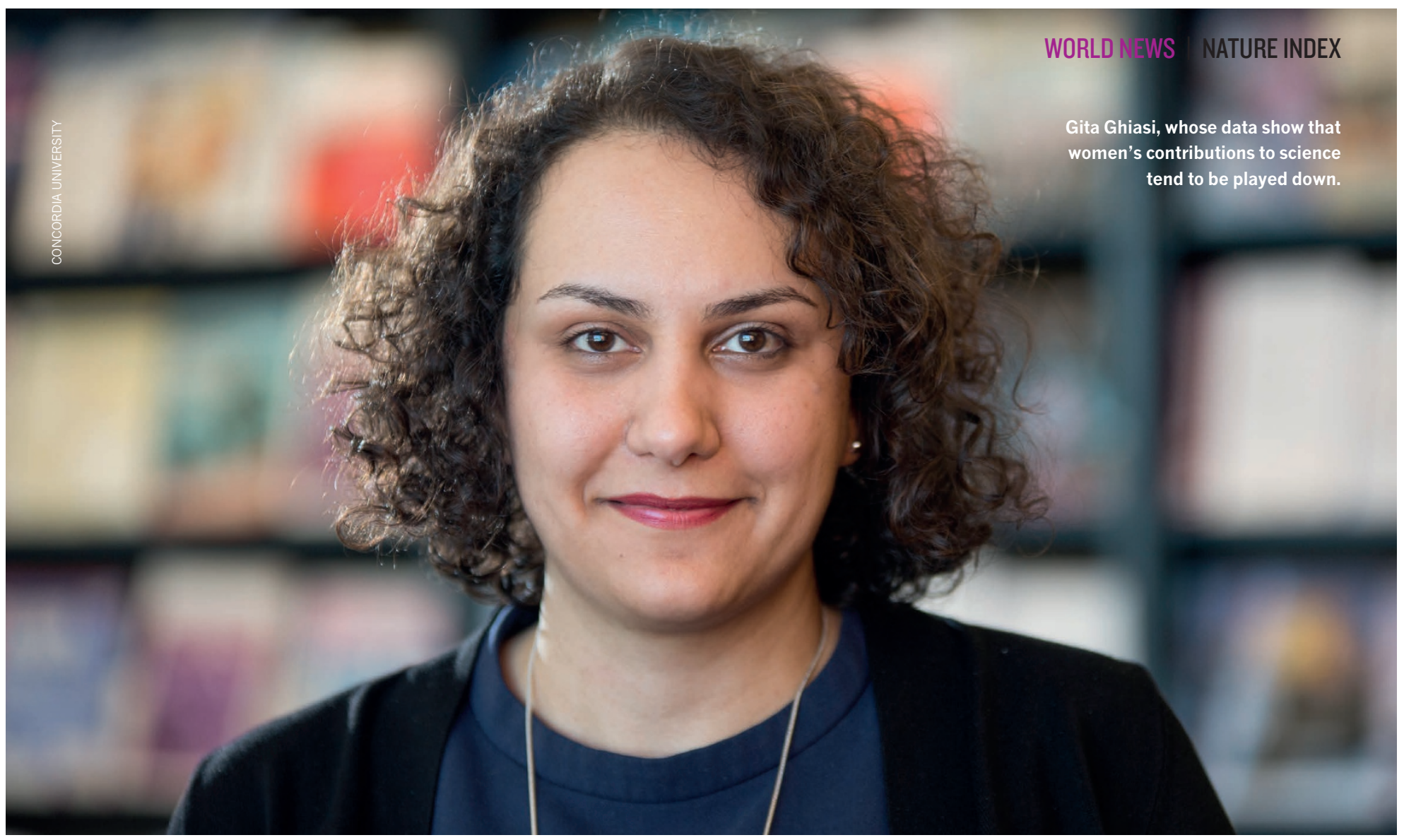

\title{
ENGINEERING A GENDER BIAS
}

\author{
Female researchers cite their own work less than men. \\ If citations are the currency of science, women are being short-changed
}

\section{BY FLYNN MURPHY}

In 2015, a Canadian team found female researchers in engineering tend to publish in more influential journals, but their work is less cited.

Now, the same team is preparing to publish evidence that women across science cite their own first-authored papers less than men. This is despite their work being cited at a higher rate by their co-authors.

Gita Ghiasi, a fourth-year $\mathrm{PhD}$ candidate in mechanical and industrial engineering at Concordia University, Québec, presented the findings at a science indicators conference in Spain last year. She said the work contributes data to growing evidence that women's scientific contributions are played down or attributed to their male peers.

Her conference paper examined citation data of more than 12 million articles published across disciplines between 2008 and 2014, gathered from the Web of Science.

It found men cite their previous first-authored papers at a $37 \%$ higher rate than women. Furthermore, women's papers were self-cited at a higher rate by their immediate co-authors.
"Women don't self-promote their work as much as men, but on the other hand, their work is important because it is highly promoted, through citations by their co-authors," Ghiasi told Nature Index.

Ghiasi's earlier study, published in PLOS $O N E$, focused on gender bias in engineering citations. Her team analysed almost a million co-authorships on more than 600,000 papers published from 2008 to 2013. It found women engineers received fewer citations, despite their papers generally being published in journals with higher impact factors.

“Overall we found women's publications receive less recognition than what should be expected from the journals that they publish their discoveries in," Ghiasi said.

Engineering is undoubtedly male dominated: four out of five authors were men. But intriguingly, the most male-dominated fields - aerospace engineering, mechanical engineering and electrical engineering - actually saw women receive as many, or more, citations.

The 'selection effect' might explain this, Ghiasi said. "In the most male dominated fields, women have to be really competent to survive, otherwise they leave the field."

Ghiasi was also surprised to discover that engineers, regardless of gender, tended to be more productive if involved in a mixed collaboration. Despite this, around half of the male engineers had no female collaborators. And both women and men were more likely to repeat their collaborations with other men. "So we can also say women, as much as men, contribute to the reproduction of these gender biases."

She said a sociological analysis might further explain the findings.

Ghiasi's collaborator, Vincent Larivière, led a cross-disciplinary 2013 gender analysis of nearly 5.5 million papers and review articles, published in Nature, which found that for every paper first-authored by a woman, two were first-authored by a man.

It also found women were less likely to be involved in international collaborations, meaning they 'profit less' from the extra citations these tend to accrue.

Flynn Murphy is a freelance reporter based in Sydney and Beijing. 